\title{
Influência da neoplasia mamária na concentração sérica de hormônios e na expressão de receptores de estrógeno e progesterona em cadelas ${ }^{1}$
}

\author{
Priscilla B. Araújo ${ }^{2}$, Daniela S. Pereira-Campinho², Diogo M.F. Silva², \\ Daniel N.A. Gonçalves ${ }^{3}$, Fabio S. Mendonça ${ }^{4}$, Francisco A.L. Souza ${ }^{4}$ \\ e Joaquim Evêncio-Neto ${ }^{4 *}$
}

\begin{abstract}
Araújo P.B., Pereira-Campinho D.S., Silva D.M.F., Gonçalves D.N.A., Mendonça F.S., Souza F.A.L. \& Evêncio-Neto J. 2018. [Influence of mammary neoplasm on the serum concentration of hormones and on the expression of estrogen and progesterone receptors in bitches.] Influência da neoplasia mamária na concentração sérica de hormônios e na expressão de receptores de estrógeno e progesterona em cadelas. Pesquisa Veterinária Brasileira 38(5):949-956. Departamento de Morfologia e Fisiologia Animal, Universidade Federal Rural de Pernambuco, Rua Dom Manoel de Medeiros s/n, Dois Irmãos, Recife, PE 52171-900, Brazil.E-mail: joaquim.evenciont@ufrpe.br

The aim of this study was to evaluate the serum concentrations of estradiol, progesterone, prolactin, the gene expression of estrogen $\alpha$ and $\beta$ and progesterone receptors in bitches with mammary neoplasms. Sixty adult crossbred bitches distributed in two groups were used. Group I consisted of 30 bitches with mammary neoplasms and Group II consisted of 30 healthy bitches without neoplasia. For the tutors, interviews were made about the disease epidemiology. After preoperative examinations, bitches with mammary neoplasia were submitted to mastectomy; fragments of the neoplasms and regional lymph nodes were collected and processed for histopathological analysis. Blood samples were collected in tubes without anticoagulant and the serum was analyzed by electrochemiluminescence to measure estradiol, progesterone and prolactin. The gene expression of the hormonal receptors was performed by means of the Real-time PCR technique, thus fragments of mammary neoplasms were collected and the RNA was extracted to obtain cDNA. Expression of the mRNA for ER $\alpha$, ER $\beta$ and PR was assessed from the amplification of these genes using specific primers. Higher serum levels of estradiol (mean $38.98 \pm 13.68 \mathrm{pg} / \mathrm{mL}$ ) were observed in bitches with malignant neoplasms when compared to the control bitches $(\mathrm{p}<0.05)$. Serum prolactin levels were higher (mean of $0.231 \pm 0.201 \mathrm{ng} / \mathrm{mL}$ ) in bitches that did not have mammary neoplasms when compared to Group I $(\mathrm{p}<0.05)$. No difference was observed for related to the progesterone levels between the groups ( $p>0.05)$. Both malignant and benign tumors expressed ER $\alpha$, ER $\beta$ and RP with no statistical difference ( $p>0.05)$ and there were no difference related to the other prognostic factors investigated (clinical staging, presence of ulceration, vascularization and aging of neoplasms). Serum estradiol levels increased significantly with the clinical staging of the disease $(\mathrm{p}<0.05)$. There was a moderate negative correlation between serum levels of estradiol and prolactin. It was concluded that serum levels of estradiol and PRL were influenced by tumor malignancy and clinical staging of neoplasms. Hormonal receptors were expressed by neoplasms, regardless of tumor type and are not associated with other classical prognostic factors, such as ulceration, vascularization or clinical staging.
\end{abstract}

INDEX TERMS: Mammary neoplasm, serum concentration, hormones, estrogen, progesterone, bitches, breast tumor, prolactin, hormone receptor, clinics.

\footnotetext{
${ }^{1}$ Recebido em 2 de junho de 2017.

Aceito para publicação em 23 de junho de 2017.

${ }^{2}$ Programa de Pós-Graduação em Medicina Veterinária, Universidade Federal Rural do Pernambuco (UFRPE), Rua Dom Manuel Medeiros s/n, Dois Irmãos, Recife, PE 52171-900, Brasil.
}

\footnotetext{
${ }^{3}$ Programa de Pós-Graduação em Ciência Animal Tropical, Universidade Federal Rural do Pernambuco (UFRPE), Rua Dom Manuel Medeiros s/n, Dois Irmãos, Recife, PE 52171-900.

${ }^{4}$ Laboratório de Diagnóstico Animal, Universidade Federal Rural do Pernambuco (UFRPE), Rua Dom Manuel Medeiros s/n, Dois Irmãos, Recife, PE 52171-900.*Autor para correspondência: joaquim.evenciont@ufrpe.br
} 
RESUMO.- 0 objetivo desse estudo foi avaliar as concentrações séricas de estradiol, progesterona e prolactina, bem como a expressão gênica dos receptores de estrógeno $\alpha$ e $\beta$ e de progesterona em cadelas com neoplasias mamárias. Foram utilizadas 60 cadelas adultas, sem raça definida que foram distribuídas em dois grupos. O Grupo I constituído por 30 cadelas portadoras de neoplasias mamárias e o Grupo II constituído por 30 cadelas saudáveis, não portadoras de neoplasia. Para os tutores, foram aplicados questionários sobre fatores epidemiológicos da doença. Após avaliação dos exames pré-operatórios, as cadelas com neoplasia mamária foram submetidas à mastectomia, coletaram-se fragmentos das neoplasias e linfonodos regionais, os quais foram processados para análise histopatológica. Para as dosagens hormonais de estradiol, progesterona e prolactina foram colhidas amostras de sangue em tubos sem anticoagulante e os soros foram submetidos à técnica de eletroquimioluminescência. A expressão gênica dos receptores hormonais foi realizada por meio da técnica de Real-time PCR e para isso foram coletados fragmentos das neoplasias mamárias e extraído o RNA para obtenção do cDNA. A expressão do mRNA para os $\mathrm{RE} \alpha, \mathrm{RE} \beta$ e RP foi avaliada a partir da amplificação desses genes utilizando primers específicos. Verificaram-se maiores níveis séricos de estradiol (média de 38,98ะ13,68pg/mL) em cadelas portadoras de neoplasias mamárias malignas quando comparadas as cadelas do grupo controle $(\mathrm{p}<0,05)$. Já os níveis séricos de prolactina foram maiores (média de $0,231 \pm 0,201 \mathrm{ng} / \mathrm{mL}$ ) nas cadelas que não possuíam neoplasias mamárias quando comparadas ao Grupo I $(\mathrm{p}<0,05)$. Para os níveis de progesterona não foram observadas diferença entre os diferentes grupos ( $p>0,05)$. Tanto os tumores malignos como os benignos expressaram RE $\alpha$, RE $\beta$ e RP, não havendo diferença $(p>0,05)$ na expressão entre tumores malignos ou benignos ou relacionada aos outros fatores prognósticos investigados (estadiamento clínico, presença de ulceração, vascularização e tempo de evolução do processo). Os níveis séricos de estradiol aumentaram significativamente com o estadiamento clínico da doença $(\mathrm{p}<0,05)$. Verificou-se moderada correlação negativa entre os níveis séricos de estradiol e prolactina. Dessa forma, conclui-se que as dosagens séricas de estradiol e PRL foram influenciadas pela malignidade do tumor e pelo estadiamento clínico das neoplasias. Os receptores hormonais foram expressos pelas neoplasias, independentemente do tipo tumoral e não estão associados aos outros fatores prognóstico clássicos, como presença de ulceração, vascularização ou estadiamento clínico.

TERMOS DE INDEXAÇ̃̃O: Neoplasia mamária, hormônios, estrógeno, progesterona, cadelas, tumor de mama, prolactina, receptor hormonal, clínica.

\section{INTRODUÇÃo}

O tumor de mama é a neoplasia que mais acomete cães no Brasil, tendo sido relatada uma frequência superior a $50 \%$ em cadelas (Queiroga \& Lopes 2002, Oliveira et al. 2003, Oliveira Filho et al. 2010, Feliciano et al. 2012, Biondi et al. 2014). Dada à quantidade de casos que surgem na rotina veterinária e importância que os cães possuem como animais de companhia, o estudo das neoplasias mamárias caninas tem ganhado destaque na rotina veterinária (Fonseca \& Daleck 2000).
Diversos fatores estão ligados à etiologia das neoplasias mamárias, entre eles estão os fatores hormonais, como os esteroides (estrógeno e progesterona), prolactina (PRL), hormônio de crescimento $(\mathrm{GH})$, fatores de crescimento (fator de crescimento tumoral - TGF e fator de crescimento epidermal - EGF) assim como os hormônios tireoidianos (Nogueira \& Brentani 1996, Silva et al. 2004, Verstegen \& Onclin 2006). A presença dos receptores de hormônios no tecido mamário é um sinal claro da dependência hormonal (Ramos et al. 2012). Assim, devido à importância que estes têm adquirido na prática clínica pelo seu valor preditivo e prognóstico, sua função nas neoplasias mamárias caninas tem sido exaustivamente estudada (Costa et al. 2002).

Os estrógenos assumem papel importante na oncogênese por serem considerados os promotores da iniciação das células mamárias cancerígenas, por aumentarem a taxa de proliferação pelo recrutamento de células não cíclicas dentro do ciclo celular (Ramos et al. 2012) e por estimular a atividade mitótica do epitélio mamário, o que eleva o risco de aparecimento de neoplasias neste órgão (Peteleiro 1994). A expressão do receptor de estrógeno (RE) é sem dúvida o mais importante biomarcador em câncer de mama em humanos, pois ele fornece o índice de sensibilidade ao tratamento endócrino (Buitrago et al. 2011). Em cadelas, é elevada a proporção de tumores benignos da mama que apresentam um aumento de receptores de estrógeno e progesterona, ao contrário, apenas uma parte das neoplasias malignas apresenta esses receptores (Johnston 1993). Em pacientes humanos, a seleção de mulheres com RE positivo no tumor primário eleva o nível de resposta clínica para 60\% (Depes et al. 2003).

A progesterona tem como funções a supressão da atividade do miométrio, a estimulação do crescimento das glândulas endometriais e a promoção do desenvolvimento do tecido alveolar mamário (Martins \& Lopes 2005). Provavelmente está envolvida com o aumento da produção de GH autócrino, que, por sua vez, pode ser capaz de estimular a síntese local ou sistêmica da secreção do fator de crescimento semelhante a insulina tipo I (IGF-I). Adicionalmente, o efeito do IGF-I pode ser influenciado por níveis locais de estradiol (17-E2). Esses resultados sugerem que todos esses hormônios e fatores podem atuar como fatores de crescimento local estimulando o desenvolvimento e/ou manutenção dos tumores mamários caninos em um modo autócrino/parácrino (Queiroga et al. 2008).

A prolactina é responsável pela manutenção da atividade secretória, não desempenhando papel sobre a proliferação celular da glândula mamária, entretanto, estimula o crescimento do tumor mamário devido à sensibilização celular aos efeitos do estrógeno, promovendo um aumento no número de receptores de estrógeno (Fonseca \& Daleck 2000). Com base em estudos morfológicos da glândula pituitária e em níveis hormonais no soro, foi sugerido que qualquer desequilíbrio de prolactina pode ser associado com a carcinogênese mamária no cão (Midsorp 2002).

0 diferente padrão de expressão dos receptores de hormônios esteroides nas neoplasias mamárias é relevante para selecionar os pacientes que podem se beneficiar da terapia endócrina e estudar protocolos terapêuticos baseados na administração de antagonistas de receptores de hormônios esteroides (Millanta et al. 2005). Dessa forma, o estudo da influência hormonal torna-se uma ferramenta 
para estabelecer o prognóstico e para avaliar se o tratamento hormonal pode ser mais benéfico que a terapia citotóxica. Partindo do pressuposto do envolvimento de hormônios na carcinogênese mamária canina, o objetivo deste trabalho foi avaliar a expressão gênica dos receptores de estrógeno $\alpha$ e $\beta$, e do receptor de progesterona, bem como os níveis séricos de estradiol, progesterona e prolactina em cadelas portadoras de neoplasias mamárias.

\section{MATERIAL E MÉTODOS}

Amostras e delineamento experimental. Para realização do estudo, foram utilizadas 60 cadelas de diferentes idades e raças divididas em dois grupos: um grupo formado por 30 fêmeas com neoplasias mamárias, oriundas de atendimento no Hospital Veterinário da Universidade Federal Rural de Pernambuco (HOVET - UFRPE) e um grupo controle composto por 30 fêmeas hígidas, sem neoplasia mamária, pertencentes a uma ONG. Esse estudo foi conduzido sob os termos e condições da Comissão de Ética no Uso de Animais (CEUA) da UFRPE, sob a licença de número 055/2015.

Os animais pertencentes ao grupo das neoplasias mamárias foram selecionados após passarem por exame clínico, hemograma e exames de imagem (radiografia torácica e ultrassonografia de abdômen). Estes últimos foram realizados para investigação de possíveis metástases pulmonar e abdominal, respectivamente, sendo que os animais positivos para estes achados foram excluídos da pesquisa. Todos os tutores responderam a um questionário sobre fatores epidemiológicos que pudessem influenciar de alguma forma o processo neoplásico.

A partir dos dados coletados através da realização da anamnese, exame clínico e aplicação do questionário, os animais foram agrupados de acordo com a classificação histológica da neoplasia, estadiamento clínico por meio do sistema tumor-nódulo-metástase (TNM) segundo classificação da Organização Mundial de Saúde (OMS) adaptado por Midsorp (2002), tempo de evolução da neoplasia, presença de ulcerações e de vascularização.

Análise histopatológica. Após a execução dos exames pré-operatórios, os animais foram encaminhados para a cirurgia de mastectomia, onde foi possível coletar fragmentos de nódulos mamários e linfonodos. Estes foram fixados em formol tamponado a $10 \%$, processados por técnicas histológicas de rotina, coradas pela hematoxilina e eosina (HE), sendo posteriormente observadas em microscópio óptico trinocular NIKON 50i. A classificação histológica das neoplasias foi realizada de acordo com Cassali et al. (2014).

Dosagem hormonal. Os hormônios estradiol, progesterona e prolactina foram dosados por meio da técnica de eletroquimioluminescência utilizando-se kits comerciais (Access Progesterone ${ }^{\circledR}$, Access Prolactin $^{\circledR}$, Access Estradiol ${ }^{\circledR}$ - Beckman Couter) seguindo as instruções do fabricante.

Para realização desta técnica, amostras de sangue dos 60 animais foram coletadas em tubos sem anticoagulante e em seguida submetidas à centrifugação, por um período de 15 minutos a $3000 \mathrm{rpm}$. As alíquotas de soro foram acondicionadas em microtubos de $1,5 \mathrm{~mL}$ e armazenadas à temperatura de $-20^{\circ} \mathrm{C}$ até o momento da dosagem.

Expressão gênica de receptores hormonais. Fragmentos dos tumores foram acondicionados em microtubos de 1,5mL e mantidos à temperatura de $-80^{\circ} \mathrm{C}$ até o momento da análise da expressão gênica. O RNA total foi extraído de cada amostra utilizando kit comercial (RNeasy ${ }^{\circledR}$ Micro Kit - QIAGEN) de acordo com o protocolo do fabricante. Para eliminar a contaminação com DNA genômico, todas as amostras de RNA foram tratadas com RNase-free DNase (Promega). O RNA
Quadro 1. Sequências dos oligonucleotídeos iniciadores utilizados no PCR em tempo real para amplificação dos genes $\mathrm{RE} \alpha, \mathrm{RE} \beta$ e RP

\begin{tabular}{ccc}
\hline $\begin{array}{c}\text { Nome do } \\
\text { oligonucleotídeo }\end{array}$ & Sequência & Tamanho \\
\hline ER $\alpha$ & S 5'AACGCCTCTGTCTCGTCTGT3' & $110 \mathrm{pb}$ \\
& A 5'GTACTCAATGCTCCCCTGGA3' & \\
ER $\beta$ & S 5'TCCCAGCAGTGCCAATAACTCAGA3' & $120 \mathrm{pb}$ \\
& A 5'TGCATACAGAAGTGACGACTGGCA3' & \\
PR & S 5'CAAACATGTCAGTGGGCAGATGC3' & 110pb \\
& A 5'CTGCCACATGGTGAGGCATAATGA3' & \\
\hline
\end{tabular}

$\mathrm{S}=$ "sense", $\mathrm{A}=$ "antisense", pb = pares de bases, $\mathrm{Re} \alpha=$ receptor de estrógeno alfa, $\operatorname{Re} \beta=$ receptor de estrógeno beta, $\mathrm{RP}=$ receptores de progesterona.

foi quantificado e sua pureza foi determinada baseada na relação de 260/280nm por espectrofotometria (BioMate ${ }^{\mathrm{TM}} 3$ - Thermo).

Para obtenção do DNA complementar total (cDNA) foi utilizado o Kit ImProm-II ${ }^{\mathrm{TM}}$ Reverse Transcription System (Promega), seguindo as recomendações do fabricante. A concentração das amostras de cDNA total foi avaliada no espectrofotômetro (BioMate ${ }^{\mathrm{TM}} 3$ - Thermo) na diluição 1:250. As amostras foram padronizadas na concentração de $100 \mathrm{ng} / \mu \mathrm{L}$ e estocadas em freezer $-80^{\circ} \mathrm{C}$.

A expressão do mRNA para os receptores de estrógeno $\alpha$ $(R E \alpha)$ e $\beta(R E \beta)$ e receptor de progesterona (RP) foi avaliada a partir da amplificação de segmentos desses genes utilizando os oligonucleotídeos iniciadores relacionados no Quadro 1, que foram construídos utilizand o o programa Primer 3 Plus (Untergasser et al. 2007) com base nas sequências nucleotídicas obtidas no GenBank NCBI (National Center for Biotechnology Information). As reações de Real-time PCR foram realizadas com o kit Quantifast ${ }^{\circledR}$ SYBR $^{\circledR}$ Green PCR (QIAGEN), em termociclador (Rotor-Gene Q da Qiagen ${ }^{\circledR}$ ), as reações foram realizadas em duplicatas com controle negativo para identificar reações inespecíficas.

Em cada reação foram utilizados um volume total de $15 \mu \mathrm{L}$ contendo, 2,0 $\mu \mathrm{L}$ do cDNA (100ng/ $\mu \mathrm{L}), 7,5 \mu \mathrm{L}$ do Quantifast ${ }^{\circledR} \mathrm{SYBR}^{\circledR}$ Green PCR Kit (QIAGEN), 0,5 $\mu \mathrm{L}$ de cada primer (10pM) e 4,5 $\mu \mathrm{L}$ de $\mathrm{H}_{2} \mathrm{O}$ Milli Q. Os seguintes ciclos foram empregados: temperatura inicial de $95^{\circ} \mathrm{C}$ por 5 min (ativação da enzima), 45 ciclos de $95^{\circ} \mathrm{C}$ por 15 segundos e $60^{\circ} \mathrm{C}$ por 30 segundos (captação da fluorescência). As condições do Melting foram: temperatura de 60 a $95^{\circ} \mathrm{C}$, com incremento de $0,5^{\circ} \mathrm{C}$ por 5 segundos. 0 gene de referência utilizado para normatizar as expressões dos genes em estudo foi o $\beta$-Actina. A quantificação relativa da expressão dos genes foi calculada pelo método 2-delta Ct (Livak \& Schmittgen 2001).

Análise estatística. Realizou-se uma análise de normalidade através dos testes de Shapiro-Wilk. A partir disso, empregou-se o teste de Tukey para comparação dos resultados das variáveis paramétricas e os testes de Kruskal-Wallis e Mann-Whitney para as variáveis não paramétricas. A correlação entre os resultados foi feita mediante o teste de Spearman (Sampaio 1998). Todos os dados foram analisados por meio do software IBM SPSS Statistics 23.0 adotando-se o nível de significância de 5,0\%.

\section{RESULTADOS E DISCUSSÃO}

As neoplasias malignas foram as mais frequentes em $76,7 \%$ (23/30) dos animais, destacando-se entre estas o carcinoma em tumor misto (26,7\%) (Quadro 2), já entre os tumores benignos o adenoma foi o tipo histológico mais frequente $(13,3 \%)$. Resultados semelhantes foram encontrados por 
Oliveira et al. (2003), que observaram que $71,8 \%$ das cadelas participantes de seu estudo eram portadoras de neoplasias malignas. Já para Queiroga \& Lopes (2002) aproximadamente $52 \%$ dos tumores mamários caninos são malignos. Frequências superiores a $70 \%$ foram descritos por Oliveira Filho et al. (2010) e Ramos et al. (2012), o que demonstra a presença marcante deste tipo de neoplasia nas cadelas do Brasil.

A maior presença de neoplasias malignas, por vezes está associada à demora na apresentação dos pacientes no hospital, pois tumores benignos podem vir a se tornar malignos (Sorenmo et al.2009). Os tumores mistos malignos foram os tipos tumorais mais encontrados por Daleck et al. (1998) e Oliveira et al. (2003), e, de acordo com Oliveira et al. (2003), os tumores de origem epitelial são os mais frequentes entre as neoplasias mamárias. Em nossos achados a neoplasia maligna mais frequente tem origem mista, achados semelhantes aos relatados por Daleck et al. (1998) e Oliveira et al. (2003).

A identificação do tipo histológico pode ser considerada um fator independente para determinação do prognóstico. Neste sentido, os carcinomas em tumor misto são caracterizados por serem extremamente variáveis, exibindo componentes mesenquimais e epiteliais, com estas últimas apresentando características de malignidade, como elevado pleomorfismo e mitoses atípicas (Cassali et al. 2014).

É importante ressaltar que o valor das classificações histológicas é baseado na capacidade de predição do comportamento biológico da neoplasia. Como existem muitas

Quadro 2. Frequência de neoplasias mamárias em cadelas atendidas no HOVET-UFRPE, distribuída conforme classificação histopatológica proposta por Cassali et al. (2014)

\begin{tabular}{cccc}
\hline \multirow{2}{*}{ Tipo de tumor } & Histopatologia & $\begin{array}{c}\text { No de } \\
\text { animais }\end{array}$ & FR (\%) \\
\hline Benignos & Adenoma & 4 & 13,3 \\
& Adenoma complexo & 2 & 6,7 \\
Malignos & Fibroadenoma & 1 & 3,3 \\
& Carcinoma anaplásico & 1 & 3,3 \\
& Carcinoma complexo & 3 & 10,0 \\
& Carcinoma mucinoso & 1 & 3,3 \\
& Carcinoma sólido & 3 & 10,0 \\
Carcinoma tubular & 4 & 13,4 \\
TOTAL & Carcinoma em tumor misto & 8 & 26,7 \\
& Carcinossarcoma & 3 & 10,0 \\
\hline
\end{tabular}

$\overline{F R}=$ Frequência relativa. classificações morfológicas propostas, as diferenças geram divergências em levantamentos epidemiológicos e em relatos de casos (Hampe \& Misdorp 1974, Monlux et al. 1977, Midsorp 2002, Cassali et al. 2014), assim, a falta de uniformização da nomenclatura utilizada dificulta a comparação dos dados epidemiológicos e medidas terapêuticas.

Os maiores níveis séricos de estradiol, com média de $38,98 \pm 13,68 \mathrm{pg} / \mathrm{mL}$ foram observados em cadelas portadoras de neoplasias mamárias malignas quando comparadas as cadelas do grupo controle $(p<0,05)$ (Quadro 3). Estes dados estão de acordo com Queiroga et al. (2008) quando verificaram que tumores malignos apresentaram maiores concentrações teciduais de estradiol e progesterona quando comparados a tumores benignos e à mamas saudáveis. Nossos resultados também reforçam os relatos de Ramos et al. (2012), que afirmam que os estrógenos são considerados os promotores da iniciação das células mamárias cancerígenas e podem aumentar a taxa de proliferação, por meio do recrutamento de células dentro do ciclo celular. Muldoon (1981) verificou que a administração de estradiol aumentou os níveis de receptores nucleares, ao contrário da atividade do receptor de progesterona, que não foi influenciada por prolactina ou estradiol. Ainda segundo este autor, os níveis de receptor de progesterona refletem a atividade dos receptores de estrógeno. Contudo, em nosso trabalho, não foi verificado associação entre estradiol e seus respectivos receptores, ou entre os receptores de estrógeno e de progesterona.

Os estrógenos são considerados como um dos fatores etiológicos dos tumores mamários em cadelas por aumentar a taxa de proliferação celular, predispondo as mesmas à alterações neoplásicas (Fonseca \& Daleck 2000). 0 aumento de estradiol sérico associado ao proestro pode estimular as células que expressam RE a sintetizarem receptor de progesterona (RP) (Sartin et al. 1992), entretanto em nossos resultados o aumento da concentração de estradiol não esteve ligado ao aumento de nenhum dos referidos receptores.

Apesar do aumento dos níveis séricos de estradiol encontrados neste trabalho não estarem relacionados ao aumento da expressão de receptores hormonais, sejam eles de estrógenos ou de progesterona, pôde-se observar que este aumento é sugestivo da influência hormonal na oncogênese, bem como pode ser considerado indicativo de pior prognóstico, uma vez que esteve relacionado às neoplasias malignas. Segundo Peteleiro (1994), os estrógenos estimulam a atividade mitótica do epitélio mamário, o que eleva o risco de aparecimento do tumor, entretanto não determina seu surgimento.

Quanto aos níveis séricos de PRL, observou-se que estes foram maiores, com média de $0,231 \pm 0,201 \mathrm{ng} / \mathrm{mL}$ nas cadelas

Quadro 3. Médias e ranks médios das dosagens hormonais e da expressão gênica de receptores analisados segundo o tipo de neoplasia

\begin{tabular}{cccccrr}
\hline Grupo & $\begin{array}{c}\text { Estradiol } \\
(\mathrm{pg} / \mathrm{mL})\end{array}$ & $\begin{array}{c}\mathrm{PRL}^{(\mathrm{A})} \\
(\mathrm{ng} / \mathrm{mL})\end{array}$ & $\begin{array}{c}\mathrm{P} 4^{(\mathrm{B})} \\
(\mathrm{ng} / \mathrm{mL})\end{array}$ & $\begin{array}{c}\mathrm{RE} \alpha^{(\mathrm{C})} \\
(\mathrm{Ct})\end{array}$ & $\begin{array}{r}\mathrm{RE}^{(\mathrm{C})} \\
(\mathrm{Ct})\end{array}$ & $\begin{array}{r}\mathrm{RP}^{(\mathrm{C})} \\
(\mathrm{Ct})\end{array}$ \\
\hline Maligno & $38,98 \pm 13,68 \mathrm{a}$ & $0,057 \pm 0,078 \mathrm{~b}$ & $20,19 \mathrm{a}$ & 9,94 & 9,91 & 11,41 \\
Benigno & $30,75 \pm 17,55 \mathrm{a}$ & $0,037 \pm 0,012 \mathrm{~b}$ & $15,00 \mathrm{a}$ & 12,75 & 12,88 & $-6,88$ \\
Controle & $15,56 \pm 9,38 \mathrm{~b}$ & $0,231 \pm 0,201 \mathrm{a}$ & $17,69 \mathrm{a}$ & - & - \\
Valor $P$ & $<0,001^{*}$ & $0,004^{*}$ & 0,623 & 0,437 & 0,385 & 0,178
\end{tabular}

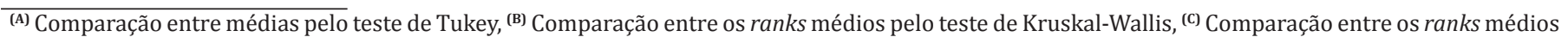
pelo teste de Mann-Whitney; Letras distintas na mesma coluna indicam diferença estatística; * Diferença significativa ao nível de 5\%; PRL = prolactina, $\mathrm{P} 4=$ progesterona, $\operatorname{Re} \alpha=$ receptor de estrógeno $\alpha, \operatorname{Re} \beta=$ receptor de estógeno $\beta, \mathrm{RP}=$ receptor de progesterona, $\mathrm{Ct}=$ Cycle Threshold . 
do grupo controle, quando comparadas aos demais grupos $(\mathrm{p}<0,05)$ (Quadro 3). Achados semelhantes foram determinados por Queiroga et al. (2005) que também verificaram maiores concentrações séricas de PRL nos animais sem tumores mamários quando comparados aos grupos portadores de neoplasias malignas ou benignas, não havendo diferença entre estes dois últimos, assim como neste trabalho.

A PRL é responsável por sensibilizar o tecido aos efeitos do estrógeno, promovendo um aumento no número de receptores deste último. Trata-se de um hormônio produzido pela glândula pituitária que na última década surgiu como um promissor fator prognóstico no câncer de mama em mulheres. Relatos conflitantes foram publicados sobre a elevação dos níveis de PRL em cães portadores desse tipo de neoplasia (Fonseca \& Daleck 2000). No entanto, segundo Vonderhaar (1999) e Goffin et al. (2002) demonstraram em seus trabalhos que as glândulas mamárias neoplásicas são capazes de sintetizar PRL, exercendo um efeito de feedback negativo na secreção de PRL pela glândula pituitária, o que justificaria os menores níveis séricos de PRL em fêmeas portadoras de neoplasias mamárias quando comparadas ao grupo controle observados neste trabalho. Há ainda estudos que indicam que hormônios esteroides e PRL interagem sinergicamente para controlar o crescimento neoplásico das glândulas mamárias em mulheres e roedores (Ormandy et al. 1997, Gutzman et al. 2004).

Não foram observadas variações significativas entre os diferentes grupos $(\mathrm{p}>0,05)$ quanto a dosagem da concentração sanguínea de progesterona, (Quadro 3), diferindo dos achados de Queiroga et al. (2005), onde os níveis teciduais desse hormônio foram maiores em tumores malignos, quando comparados aos tumores benignos. Em cães, a progesterona é responsável por promover tumores mamários através da estimulação da produção de GH pelas células da glândula mamária. A progesterona pode estar ligada ao surgimento de neoplasias benignas, pela indução de um ambiente altamente proliferativo e o efeito da interação entre a progesterona e o estrógeno pode estar diretamente ligado ao aparecimento de tumores mamários em cadelas (Martins \& Lopes 2005), entretanto em nosso trabalho não foi verificada alterações nos níveis séricos de progesteronas relacionadas a qualquer característica observada.

Tanto os tumores malignos quanto os benignos expressaram $R E \alpha, R E \beta$ e RP, não havendo diferença $(p>0,05)$ na expressão desses receptores hormonais nos diferentes tipos de neoplasias (Quadro 3). A presença dos receptores é sinal claro da dependência hormonal das neoplasias. Nos tumores malignos, a expressão dos genes que codificam os RE e RP podem estar diminuídas, sobretudo em neoplasias de maior grau de malignidade ou nas fases mais avançadas da doença (Peteleiro 1994).

Apesar de não haver diferença estatística, é possível observar que nas neoplasias benignas houve uma maior expressão de RE do que nas neoplasias malignas, enquanto RP foi mais expresso nos tumores malignos. Nos achados de Ramos et al. (2012) afirmam que houve uma maior tendência para expressão dos receptores no grupo dos animais controle e uma menor expressão nos grupos dos animais portadores de neoplasias malignas. Além disso, estes mesmos autores verificaram uma maior expressão de RE $\alpha$ em relação a RE $\beta$. Entretanto RE $\alpha, \mathrm{RE} \beta$ e RP foram observados em neoplasias mamárias benignas, malignas e no grupo controle.

$\mathrm{Na}$ avaliação da expressão dos RE e RP, os resultados obtidos demonstram que os dois grupos de animais, com lesões benignas ou malignas, expressam RE $\alpha, \mathrm{RE} \beta$ e RP. Animais com tumores de mama com RE e RP, ou somente RE, apresentam melhor prognóstico que aqueles que possuem somente RP, visto que a presença dos primeiros se correlaciona com tumores bem diferenciados (Sartin et al. 1992). Assim a expressão de ambos os receptores em tipos histológicos malignos e benignos sugere um melhor prognóstico para as pacientes, por tratar-se de neoplasias melhor diferenciadas.

Quanto ao estadiamento clínico da doença (Quadro 4) verificou-se que os níveis séricos de estradiol aumentaram significativamente $(\mathrm{p}<0,05)$, sendo observados menores níveis no grupo controle. 0 estrógeno tem importância no desenvolvimento da glândula mamária normal e influencia o crescimento e comportamento dos tumores mamários das mulheres e nas cadelas (Fonseca \& Daleck 2000). Já a PRL, apesar de não diferir estatisticamente $(p>0,05)$ entre os estadiamentos, foram menores nos animais com o estadiamento clínico mais avançado. Esse achado pode sugerir, conforme observado por Vonderhaar (1999) e Goffin et al. (2002), que as células cancerígenas dos tumores mamários em estádios mais avançados seriam capazes de sintetizar PRL, produzindo um efeito de feedbak negativo o que, por sua vez, diminuiria os níveis séricos deste hormônio.

Em relação ao tempo de evolução, quando comparadas os níveis séricos das dosagens hormonais, observaram-se maiores concentrações de estradiol nos animais com menor tempo de evolução da doença $(\mathrm{p}<0,05)$, e maiores níveis séricos de PRL nos animais do grupo controle $(\mathrm{p}<0,05)$ (Quadro 4). Já para a expressão dos receptores hormonais não houve diferença significativa entre os grupos ( $p>0,05)$.

Sabe-se que com o avançar do tempo, as neoplasias tendem a assumir características de maior malignidade, que incluem a perda da expressão dos receptores hormonais (Ramos et al. 2012), e perda da dependência hormonal (Fonseca \& Daleck 2000). Assim, espera-se obervar em processos com menores períodos de evolução uma maior expressão de receptores hormonais, bem como uma maior dependência hormonal que pode ser identificada a partir da observação de maiores níveis séricos hormonais, reforçando assim os resultados encontrados no presente trabalho.

Convém ressaltar também, que muitos proprietários relatam um grande intervalo entre a observação do tumor e a apresentação do animal ao Médico Veterinário, que por vezes só acontece quando há ulceração ou quando o crescimento passa a acontecer de forma bastante acelerada. Mais de 50\% dos proprietários relataram que esperaram mais de 1 ano para levarem suas cadelas para consulta. Sabe-se que o diagnóstico e o tratamento precoces proporcionam um melhor prognóstico aos pacientes (Oliveira et al. 2003).

No que se refere a tumores ulcerados, observou-se menores concentrações séricas de estradiol no grupo controle $(p<0,05)$, que também apresentou maiores concentrações de prolactina $(\mathrm{p}<0,05)$. Não houve diferença estatística $(\mathrm{p}>0,05)$ para expressão dos receptores hormonais (Quadro 4). Queiroga et al. (2005) observaram que os níveis de prolactina mais altos estão relacionados com a presença de ulceração e aderência a pele e tecidos adjacentes. Segundo Oliveira et al. (2003) a ulceração é considerada um fator de malignidade, o que indica que o resultado observado pode indicar o possível papel da PRL na determinação do prognóstico de cadelas portadoras de neoplasias mamárias, contudo, são necessárias maiores investigações no intuito de melhor determinar a importância deste achado. 
Quadro 4. Comparação dos ranks médios das dosagens hormonais e da expressão gênica de receptores, analisados segundo o estadiamento, tempo de evolução, presença de ulceração e vascularização em neoplasias mamárias de cadelas

\begin{tabular}{|c|c|c|c|c|c|c|c|c|c|c|c|c|c|}
\hline Variável & Categoria & $\begin{array}{c}\text { Estradiol } \\
(\mathrm{pg} / \mathrm{mL})\end{array}$ & $\begin{array}{l}\text { Valor } \\
\text { de p }\end{array}$ & $\begin{array}{c}\text { PRL } \\
\text { (ng/mL) }\end{array}$ & $\begin{array}{l}\text { Valor } \\
\text { de p }\end{array}$ & $\begin{array}{c}\mathrm{P} 4 \\
(\mathrm{ng} / \mathrm{mL})\end{array}$ & $\begin{array}{c}\text { Valor } \\
\text { de p }\end{array}$ & $\begin{array}{l}\mathrm{RE} \alpha \\
(\mathrm{Ct})\end{array}$ & $\begin{array}{l}\text { Valor } \\
\text { de p }\end{array}$ & $\begin{array}{l}\operatorname{RE} \beta \\
(\mathrm{Ct})\end{array}$ & $\begin{array}{l}\text { Valor } \\
\text { de p }\end{array}$ & $\begin{array}{c}\mathrm{RP} \\
(\mathrm{Ct})\end{array}$ & $\begin{array}{c}\text { Valor } \\
\text { de p }\end{array}$ \\
\hline \multirow[t]{5}{*}{ Estadiamento $^{(\mathrm{A})}$} & I & 18,33 & & 16,67 & & 14,67 & & 11,33 & & 14,33 & & 11,83 & \\
\hline & II & 22,30 & & 17,20 & & 19,70 & & 9,20 & & 11,60 & & 7,70 & \\
\hline & III & 23,94 & & 10,75 & & 21,50 & & 10,25 & & 6,88 & & 12,88 & \\
\hline & IV & 33,88 & & 11,38 & & 17,13 & & 12,00 & & 13,50 & & 8,25 & \\
\hline & Controle & 10,78 & $0,031^{*}$ & 24,91 & 0,390 & 17,69 & 0,708 & - & 0,903 & - & 0,139 & - & 0,369 \\
\hline \multirow[t]{4}{*}{ Tempo de evolução ${ }^{(A)}$} & $<6$ meses & 28,67 & & 16,33 & & 14,33 & & 12,00 & & 16,17 & & 12,67 & \\
\hline & 6 a 12 meses & 23,07 & & 13,43 & & 18,64 & & 13,57 & & 7,50 & & 9,64 & \\
\hline & $>12$ meses & 24,60 & & 12,45 & & 20,95 & & 7,90 & & 10,90 & & 10,45 & \\
\hline & Controle & 10,78 & $0,001^{*}$ & 24,91 & $0,011^{*}$ & 17,69 & 0,775 & - & 0,135 & - & 0,099 & - & 0,759 \\
\hline \multirow[t]{3}{*}{ Ulceração ${ }^{(\mathrm{B})}$} & Sim & 24,88 & & 16,25 & & 23,50 & & 9,25 & & 8,75 & & 12,75 & \\
\hline & Não & 24,63 & & 12,66 & & 18,06 & & 10,81 & & 10,94 & & 9,94 & \\
\hline & Controle & 10,78 & $<0,001^{*}$ & 24,91 & $0,004^{*}$ & 17,69 & 0,599 & - & 0,682 & - & 0,554 & - & 0,437 \\
\hline \multirow[t]{2}{*}{ Vascularização (B) } & Sim & 29,20 & & 13,00 & & 16,40 & & 6,80 & & 7,80 & & 10,10 & \\
\hline & Não & 23,17 & & 13,50 & & 20,07 & & 11,73 & & 11,40 & & 10,63 & \\
\hline Controle & 10,78 & $<0,001^{*}$ & 24,91 & $0,005^{*}$ & 17,69 & 0,731 & - & 0,119 & - & 0,266 & - & 0,866 & \\
\hline
\end{tabular}

(A) Comparação entre os ranks médios pelo teste de Kruskal-Wallis, (B) comparação entre os ranks médios pelo teste de Mann-Whitney; * diferença significativa ao nível de 5\%; PRL = prolactina, $\mathrm{P} 4=$ progesterona, $\mathrm{Re} \alpha=$ receptor de estrógeno $\alpha$, Re $\beta=$ receptor de estrógeno $\beta$, RP = receptor de progesterona.

Quanto à presença de vascularização nas neoplasias estudadas, observou-se que os maiores níveis séricos de estradiol estiveram presentes nas cadelas portadoras de neoplasias vascularizadas $(\mathrm{p}<0,05)$, enquanto os maiores níveis de PRL foram observados nas cadelas do grupo controle $(p<0,05)$. Quanto à expressão dos receptores hormonais, não foi observada diferença estatística $(p>0,05)$ (Quadro 4).

De acordo com Illera et al. (2006), os altos níveis de estradiol podem aumentar o fator de crescimento endotelial vascular (VEGF), um fator chave para a angiogênese. Sabe-se também que a vascularização é um fator crucial para a continuidade do crescimento dos tumores, e sobrevivência das células neoplásicas (Midsorp 2002). Como o crescimento e o risco de metástases dependem da neoangiogênese adjacentes ao tumor, a presença de uma maior vascularização nas neoplasias pode estar associada a um prognóstico mais reservado, que neste estudo, está associado também aos maiores níveis séricos de estradiol, o que permite sugerir que os altos níveis deste hormônio sejam um indicador de mau prognóstico associado à angiogênese, concordando com os achados de Illera et al. (2006), onde propõem que o hormônio em questão pode ser capaz de estimular fatores angiogênicos, diretamente ligados a neoplasias mais agressivas, com maior poder invasivo, e, consequentemente, de prognóstico desfavorável.

Os maiores níveis de estrógeno estiveram associados a neoplasias malignas, com estadimento clínico mais avançado, ulceradas e vascularizadas. Esses resultados podem indicar o papel dos estrógenos no desenvolvimento tumoral, exercendo um efeito mitogênico nas células tumorais, o que favoreceria a progressão tumoral.

Neste trabalho, os níveis de esteroides não foram influenciados pela expressão do receptor correspondente no tecido mamário. Verificou-se ainda moderada correlação negativa entre os níveis séricos de estradiol e PRL (Quadro 5). No entanto, Swenson (1996) afirma que os estrogênios aumentam a secreção de PRL.
Quadro 5. Análise da correlação das dosagens hormonais e da expressão gênica de receptores de acordo com os grupos (maligno, benigno e controle) através do teste de Spearman

\begin{tabular}{cccccc}
\hline Parâmetros & Estradiol & P4 & PRL & RE $\alpha$ & RE $\beta$ \\
\hline Estradiol & & & & & \\
(Valor P) & & & & & \\
Progesterona & 0,186 & & & & \\
(Valor P) & $(0,278)$ & & & & \\
PRL & $-0,467$ & $-0,268$ & & & \\
(Valor P) & $(0,004)^{*}$ & $(0,114)$ & & & \\
RE $\alpha$ & 0,212 & 0,149 & $-0,158$ & & \\
(Valor P) & $(0,369)$ & $(0,531)$ & $(0,506)$ & & \\
RE $\beta$ & $-0,143$ & 0,265 & 0,040 & $-0,049$ & \\
(Valor P) & $(0,548)$ & $(0,259)$ & $(0,867)$ & $(0,838)$ & \\
RP & $-0,173$ & $-0,374$ & $-0,164$ & $-0,121$ & 0,144 \\
(Valor P) & $(0,466)$ & $(0,104)$ & $(0,490)$ & $(0,611)$ & $(0,544)$
\end{tabular}

*Associação significativa ao nível de 5\%; PRL= prolactina, $\mathrm{P} 4$ = progesterona, $\operatorname{Re} \alpha=$ receptor de estrógeno $\alpha, \operatorname{Re} \beta=$ receptor de estógeno $\beta, \mathrm{RP}=$ receptor de progesterona.

Até o momento não foram verificadas associações entre os níveis séricos de PRL e estradiol em cadelas portadoras de neoplasias mamárias, contudo, individualmente, ambos são citados por possuírem um papel promotor na carcinogênese mamária (Fonseca \& Daleck 2000, Buitrago et al. 2011, Feliciano et al. 2012).

De acordo com Kojima etal. (1996), o risco de desenvolvimento do câncer de mama é essencialmente determinado pela intensidade e duração da exposição do epitélio mamário à ação conjunta da PRL e do estrógeno. Nossos resultados mostraram que quanto maior a concentração sérica de estradiol, menor os níveis de PRL, estando o estradiol associado às características de malignidade, enquanto para PRL não foi 
verificada tal associação. Assim, são necessários mais estudos que possam esclarecer o papel da interação de estradiol e PRL na oncogênese mamária.

\section{CONCLUSÕES}

As concentrações séricas de estradiol e PRL foram influenciadas pela malignidade do tumor mamário e pelo estadiamento clínico da doença, variações que reafirmam o envolvimento destes com a fisiologia do processo tumoral. No entanto, os RE e RP não foram influenciados pelos níveis séricos de estrógeno e progesterona.

Os receptores hormonais foram expressos pelas neoplasias, independentemente do tipo tumoral, e não estão associados aos outros fatores prognóstico clássicos, como presença de ulceração, vascularização ou estadiamento clínico. A expressão de receptores hormonais, independente do tipo tumoral ou estadiamento clínico traz a possibilidade da utilização de tratamentos com seus antagonistas e fármacos anti-hormonais, que infelizmente ainda não fazem parte da rotina veterinária.

\section{REFERÊNCIAS}

Biondi L.R., Gentile L.B., Rego A.A.M.S., Noronha N.P. \& Dagli M.L.Z. 2014. Canine mammary tumors in Santos, Brazil: clinicopathological and survival profile. Braz. J. Vet. Res. Anim. Sci. 51(3):252-262. http://dx.doi. org/10.11606/issn.1678-4456.v51i3p252-262.

Buitrago F., Uemura G. \& Sena M.C.F. 2011. Fatores prognósticos em câncer de mama. Comun. Ciênc. Saúde 22:69-82.

Cassali G.G., Lavalle G.E., De Nardi A., Ferreira E., Bertagnolli A.C., EstrelaLima A., Alessi A.C., Daleck C.R., Salgado B.S., Fernandes C.G., Sobral A.C., Amorim R.L., Gamba C.O., Damasceno K.A., Auler P.A., Magalhães G.M., Silva J.O., Raposo J.B., Fereira A.M.R., Oliveria L.O., Malm C., Zuccari D.A.P.C., Tanaka N.M., Ribeiro L.R., Campos L.C., Souza C.M., Leite J.S., Soares L.M.C., Cavalcanti M.F., Fonteles Z.G.C., Schuch I.D., Paniago J., Oliveira T.S., Terra E.M., Castanheira T.L.L., Feliz A.O.C., Carvalho G.D., Guim T.N., Garrido E., Fernandes S.C., Maia F.C.L., Dagli M.L.Z., Rocha N.S., Fukumasu H., Grandi F., Machado J.P., Silva S.M.M.S., Bezerril J.E., Frehse M.S., Paes De Almeida E.C. \& Campos C.B. 2014. Consensus for the diagnosis, prognosis and treatment of canine mammary tumors, 2013. Braz. J. Vet. Pathol. 7(2):38-69.

Costa S.D., Lange S., Klinga K., Merkle E. \& Kaufmann M. 2002. Factors influencing the prognostic role of oestrogen and progesterone receptor levels in breast cancer: results of the analysis of 670 patients with 11 years of follow-up. Eur. J. Cancer 38(10):1329-1334. http://dx.doi.org/10.1016/ S0959-8049(02)00067-9. PMid:12091062.

Daleck C.R., Franceschini P.H., Alessi A.C., Santana Á.E. \& Martins M.I.M. 1998. Aspectos clínicos e cirúrgicos do tumor mamário canino. Ciência Rural 28(1):95-100. http://dx.doi.org/10.1590/S0103-84781998000100016.

Depes D.B., Souza M.A., Ribalta J.C.L., Alves M.T.S., Kemp C. \& Lima G.R. 2003. Alterações na expressão do antígeno nuclear de proliferação celular e dos receptores de estrogênio e de progesterona provocadas pela quimioterapia primária no carcinoma de mama. Revta Bras. Ginecol. Obstet. 25(8):545552. http://dx.doi.org/10.1590/S0100-72032003000800002.

Feliciano M.A.R., Silva A.S., Peixoto R.V.R., Galera P.D. \& Vicente W.R.R. 2012. Estudo clínico, histopatológico e imunoistoquímico de neoplasias mamárias em cadelas. Arq. Bras. Med. Vet. Zootec. 64(5):1094-1100. http://dx.doi. org/10.1590/S0102-09352012000500002.

Fonseca C.S. \& Daleck C.R. 2000. Neoplasias mamárias em cadelas: influência hormonal e efeitos da ovario-histerectomia como terapia adjuvante. Ciência Rural 30(4):731-735. http://dx.doi.org/10.1590/S0103-84782000000400030.

Goffin V., Binart N., Touraine P. \& Kelly P.A. 2002. Prolactin: the new biology of an old hormone. Ann. Rev. Physiol. 64(1):47-67. http://dx.doi.org/10.1146/ annurev.physiol.64.081501.131049. PMid:11826263.
Gutzman J.H., Miller K.K. \& Schuler L.A. 2004. Endogenous human prolactin and not exogenous human prolactin induces estrogen receptor alfa and prolactin receptor expression and increases estrogen responsiveness in breast cancer cells. J. Steroid Biochem. Mol. Biol. 88(1):69-77. http:// dx.doi.org/10.1016/j.jsbmb.2003.10.008. PMid:15026085.

Hampe J.F. \& Misdorp W. 1974. Tumors and dysplasias of the mammary gland. Bull. World Health Org. 50(1/2):111-133. PMid:4371737.

Illera J.C., Pérez-Alenza M.D., Nieto A., Jiménez M.A., Silvan G., Dunner S. \& Peña L. 2006. Steroids and receptors in canine mammary cancer. Steroids 71(7):541-548. http://dx.doi.org/10.1016/j.steroids.2005.11.007. PMid:16631217.

Johnston S.D. 1993. Reproductive systems, p.2177-2199. In: Slatter D. (Ed), Textbook of Small Animal Surgery. 2nd ed. W.B. Saunders, Philadelphia.

Kojima H., Fukazawa Y., Sato T., Enari M., Matsuzawa A., Tsunoda S., Nagasawa H., Ohta Y. \& Iguchi T. 1996. Apoptosis of pregnancy-dependent mammary tumor and transplantable pregnancy-dependent mammary tumor in mice. Cancer Lett. 110(1/2):113-121. http://dx.doi.org/10.1016/S03043835(96)04469-2. PMid:9018089.

Livak K.J. \& Schmittgen T.D. 2001. Analysis of relative gene expression data using real-time quantitative PCR and the 2(-Delta Delta C(T)) Method. Methods 25(4):402-408. http://dx.doi.org/10.1006/meth.2001.1262. PMid:11846609.

Martins L.R. \& Lopes M.D. 2005. Pseudociese canina. Revta Bras. Reprod. Anim. 29:137-141.

Midsorp W. 2002. Tumors of the mamary gland, p.575-606. In: Meuten D.J. (Ed), Tumors in Domestic Animals. 4th ed. Iowa State Press, Ames.

Millanta F., Calandrella M., Bari G., Niccolini M., Vannozzi I. \& Poli A. 2005. Comparison of steroid receptor expression in normal, dysplastic and neoplastic canine and feline mammary tissues. Res. Vet. Sci. 79(3):225232. http://dx.doi.org/10.1016/j.rvsc.2005.02.002. PMid:16054892.

Monlux A.W., Roszel J.F., MacVean D.W. \& Palmer T.W. 1977. Classification of epithelial canine mammary tumors in a defined population. Vet. Pathol. 14(3):194-217. http://dx.doi.org/10.1177/030098587701400303. PMid:196383.

Muldoon T.G. 1981. Interplay between estradiol and prolactin in the regulation of steroid hormone receptor levels, nature, and functionality in normal mouse mammary tissue. Endocrinology 109(5):1339-1346. http://dx.doi. org/10.1210/endo-109-5-1339. PMid:7197617.

Nogueira C.R. \& Brentani M.M. 1996. Triiodothyronine mimics the effects of estrogen in breast cancer cell lines. J. Steroid Biochem. Mol. Biol. 59(3/4):271-279. http://dx.doi.org/10.1016/S0960-0760(96)00117-3. PMid:9010319.

Oliveira Filho J.C., Kommers G.D., Masuda E.K., Marques B.F.M.P.P., Fighera R.A., Irigoyen L.F. \& Barros C.L.S. 2010. Estudo retrospectivo de 1.647 tumores mamários em cães. Pesq. Vet. Bras. 30(2):177-185. http://dx.doi. org/10.1590/S0100-736X2010000200014.

Oliveira L.O., Oliveira R.T., Loretti L.P., Rodrigues R.P. \& Driemeier D. 2003. Aspectos epidemiológicos da neoplasia mamária canina. Acta Scient. Vet. 31(2):105-110.

Ormandy C.J., Hall R.E., Manning D.L., Robertson J.F.R., Blamey R.W., Kelly P.A., Nicholson R.I. \& Sutherland R.L. 1997. Coexpression and cross-regulation of the prolactin receptor and sex steroid hormone receptors in breast câncer. J. Clin. Endocrinol. Metabol. 82(11):3692-3699. PMid:9360527.

Peteleiro M.C. 1994. Tumores mamários na cadela e na gata. Revta Port. Ciênc. Vet. 89:10-29.

Queiroga F. \& Lopes C. 2002. Tumores mamários caninos: novas perspectivas. Anais Congresso de Ciências Veterinárias, Oeiras, Portugal, p.183-190.

Queiroga F.L., Pérez-Alenza M.D., Silvan G., Peña L., Lopes C. \& Illera J.C. 2005. Role of steroid hormones and prolactin in canine mammary cancer. J. 
Steroid Biochem. Mol. Biol. 94(1/3):181-187. http://dx.doi.org/10.1016/j. jsbmb.2004.12.014. PMid:15862964.

Queiroga F.L., Pérez-Alenza M.D., Silvan G., Peña L., Lopes C.S. \& Illera J.C. 2008. Crosstalk between GH/IGF-I axis and steroid hormones (progesterone, $17 \beta$-estradiol) in canine mammary tumours. J. Steroid Biochem. Mol. Biol. 110(1/2):76-82. http://dx.doi.org/10.1016/j.jsbmb.2008.02.005. PMid:18367392.

Ramos R.S., Avanzi B.R., Volpato R., Pignaton W., Castan E.P., Costa F.A.A. \& Lopes M.D. 2012. Expressão gênica dos RE $\alpha, R E \beta$, e PR em tumores mamários de cadelas por meio do q-PCR. Arq. Bras. Med. Vet. Zootec. 64(6):1471-1477. http://dx.doi.org/10.1590/S0102-09352012000600010.

Sampaio I.B.M. 1998. Estatística Aplicada à Experimentação Animal. Fundação de Ensino e Pesquisa em Medicina Veterinária e Zootecnia, Belo Horizonte, p.219-221.

Sartin E.A., Barnes S., Kwapien P. \& Wolfe L.G. 1992. Estrogen and progesterone receptor status of mammary carcinomas and correlation with clinicai outcome in dogs. Am. J. Vet. Res. 53(11):2196-2200. PMid:1466519.

Silva A.E., Serakides R. \& Cassali G.D.C. 2004. Carcinogênese hormonal e neoplasias hormônio-dependentes. Ciência Rural 34(2):625-633. http:// dx.doi.org/10.1590/S0103-84782004000200048.
Sorenmo K.U., Kristiansen V.M., Cofone M.A., Shofer F.S., Breen A.M., Langeland M., Mongil C.M., Grondahl A.M., Teige J. \& Goldschmidt M.H. 2009. Canine mammary gland tumors: a histological continuum from benign to malignant; clinical and histopathological evidence. Vet. Comp. Oncol. 7(3):162-172. http://dx.doi.org/10.1111/j.14765829.2009.00184.x. PMid:19691645.

Swenson M.J. 1996. Dukes: fisiologia dos animais domésticos. 11aㅡ ed. Guanabara Koogan, Rio de Janeiro, p.651-673.

Untergasser A., Nijveen H., Rao X., Bisseling T., Geurts R. \& Leunissen J.A.M. 2007. Primer3Plus, an enhanced web interface to Primer3. Nucleic Acids Res. 35(Web Server):71-74. http://dx.doi.org/10.1093/nar/gkm306. PMid:17485472.

Verstegen J.P. \& Onclin K. 2006. Prolactin and anti-prolactinic agents in thepathophysiology and treatment of mammary tumors in the dog. Proc. N. Am. Vet. Conf. 7:7-11.

Vonderhaar B.K. 1999. Prolactin involvement in breast cancer. Endoc. Relat. Cancer 6(3):389-404. http://dx.doi.org/10.1677/erc.0.0060389. PMid:10516853. 